\title{
Validity and reliability of fluoroscopy for digital radiography: a new way to evaluate diaphragmatic mobility
}

\author{
Bruna Estima Leal ${ }^{1}$, Márcia Aparecida Gonçalves ${ }^{1}$, Liseane Gonçalves Lisboa², Larissa Martins Schmitz Linné2 \\ Michelle Gonçalves de Souza Tavares ${ }^{3}$, Wellington Pereira Yamaguti ${ }^{4}$ and Elaine Paulin ${ }^{1,5^{*}}$
}

\begin{abstract}
Background: Fluoroscopy is considered the most accurate method to evaluate the diaphragm, yet most existing methods for measuring diaphragmatic mobility using fluoroscopy are complex. To assess the validity and reliability of a new evaluation method of diaphragmatic motion using fluoroscopy by digital radiography of healthy adults.

Methods: Twenty-six adults were evaluated, according to the parameters: anthropometry and pulmonary function test. The evaluation of diaphragm mobility by means of fluoroscopy by digital radiography method was randomly conducted by two raters (A and B). The Pearson correlation coefficient and the intraclass correlation coefficient (ICC) were used to assess the concurrent validity. The inter-rater and intra-rater reliability of the measurement of diaphragmatic motion was determined using ICC and a confidence interval of 95\%.

Results: There was a relationship in the assessment of the concurrent validity. There was good inter-rater reliability for right hemidiaphragm mobility and moderate reliability for left hemidiaphragm in the first assessment. In the second assessment, there was good reliability for the mobility of both hemidiaphragms. There was good intra-rater reliability in the mobility of both hemidiaphragms for raters $A$ and $B$.

Conclusion: The evaluation of diaphragmatic motion using fluoroscopy by digital radiography proved to be a valid and reliable method of healthy adults.
\end{abstract}

Keywords: Diaphragm, Fluoroscopy, Validity, Reproducibility of results

\section{Background}

Specifically evaluating the mobility of the diaphragm is important for understanding and diagnosing possible alterations in the muscle, which can be compromised in several ways: due to central or peripheral nervous system dysfunction, muscular disease and thoracic or abdominal disease, resulting in a reduction of mobility or paralysis [1-6].

In clinical practice it is essential to use valid and reliable methods for assessing diaphragmatic dysfunction, because the use of subjective methods may compromise the results.

\footnotetext{
* Correspondence: elaine.paulin@udesc.br

'Physical Therapy Department,Santa Catarina State University (UDESC), Florianopolis, SC, Brazil

${ }^{5}$ Santa Catarina State University (UDESC), Rua Pascoal Simone, 358,

Coqueiros, Florianópolis, SC, BrazilCEP: 88080-350

Full list of author information is available at the end of the article
}

Therefore, it is extremely important that any assessment method have its validity and reliability tested to ensure that the error in the measurement is reduced [7-9].

There are several imaging methods that assess diaphragmatic mobility: fluoroscopy [10-13], ultrasound [14, 15], computed tomography [16], magnetic resonance [17-19], and chest radiography [20,21]. Each technique has its particularities in the observation of the diaphragm, considering cost, radiation exposure and method availability in the study environment $[5,22]$.

Considering all the methods for evaluating diaphragmatic mobility, the fluoroscopy is the most accurade method for assessing the diaphragm muscle because it provides dynamic images of the diaphragm and direct visualization of diaphragmatic movements in real time [5]. However, there are no studies confirming the validity and reliability of digital radiography fluoroscopy to assess diaphragmatic excursion. 
Diaphragmatic mobility can be measured by the fluoroscopy method in various ways, but those forms reported in the literature are not simple to be obtained [10-13]. Some measures require radiographic impression for analysis [13], others, those recorded on video [10,11], are not always available on fluoroscopy devices, and in other measurements, image calculations involve several complex lines for obtaining the value of diaphragmatic mobility [13].

Since fluoroscopy assesses diaphragm motion in real time [5], and the ways reported in the literature for measuring diaphragm mobility by means of fluoroscopy are complex [10-13], and there is no literature studies investigating its validity and reliability, we propose creating a new method and a new measurement procedure that is much more easily obtained in clinical practice, using fluoroscopy by digital radiography.

Thus, the aim of this study was to assess the validity and reliability (inter- and intra-rate) of a new method of evaluation of diaphragmatic mobility using fluoroscopy by digital radiography.

\section{Methods \\ Sample}

In this study, 26 apparently healthy adults were included in a convenience sample. They were recruited among students and employees of the Universidade do Estado de Santa Catarina (Brazil), as well as their relatives. The sample size calculation was based on Bonett [23] and Fleiss [24] studies. According to these authors, to assess test reliability, a sample can vary between 15 and 20 participants.

Inclusion criteria for the study were: non-smoking healthy subjects with normal pulmonary function (FVC and $\mathrm{FEV}_{1} \geq 80 \%$ predicted and $\mathrm{FEV}_{1} / \mathrm{FVC} \geq 0.7$ ) without cardiorespiratory or neurological diseases, women who were not pregnant or with suspected pregnancy, participants without a diagnosis of cancer, or disease history or any other alteration that could impair the evaluations. Exclusion criteria were: participants who presented clinical complications of respiratory nature, inability to perform any of the procedures used in the study (lack of understanding or collaboration), clinical complications of the respiratory system and those who requested exclusion from the study. This study was approved (16696413.8.0000.0118) by the Research Ethics Committee of the Universidade do Estado de Santa Catarina (UDESC), Brazil, and all participants provided written informed consent.

\section{Study design}

This is a cross-sectional study, with validity and reliability test, which assessed the agreement degree of diaphragmatic mobility by means of X-ray digital fluoroscopy [25].

Initially, anthropometric and pulmonary parameters were evaluated. Following, digital X-rays were scheduled in order to measure diaphragmatic excursion. Before the fluoroscopy examination, training of the diaphragm through diaphragmatic breathing exercise was performed, slow vital capacity (SVC) was also measured before and during the examination.

The examination of diaphragmatic motion by digital radiography fluoroscopy was randomly performed by two radiologists (raters $\mathrm{A}$ and $\mathrm{B}$ ), and subsequently digital diaphragmatic mobility $\left(\mathrm{DM}_{\mathrm{dig}}\right)$ was measured by both raters, aiming to evaluate the intra-rater and interrater reliability. Diaphragmatic mobility by distance $\left(\mathrm{DM}_{\text {dist }}\right)$ [20] was measured by rater $\mathrm{A}$, to evaluate the validity of the method.

\section{Collection procedures \\ Anthropometry}

For measurement of body mass and height, a previously calibrated scale and a stadiometer (Welmy model W200/5) were used respectively. Once the anthropometric values were obtained (weight and height), the body mass index (BMI) was calculated using the equation: body mass/ (height $)^{2}\left(\mathrm{~kg} / \mathrm{m}^{2}\right)$. Subjects were classified according to BMI as underweight $\left(\leq 18.5 \mathrm{~kg} / \mathrm{m}^{2}\right)$, normal $\left(18.5-24.9 \mathrm{~kg} / \mathrm{m}^{2}\right)$, overweight $\left(25-29.9 \mathrm{~kg} / \mathrm{m}^{2}\right)$ and obese $\left(\geq 30 \mathrm{~kg} / \mathrm{m}^{2}\right)[26]$.

\section{Pulmonary function test}

The pulmonary function test was performed using a previously calibrated spirometer in accordance with the methods and criteria recommended by the American Thoracic Society [27]. For assessment of forced vital capacity (FVC), forced expiratory volume in the first second $\left(\mathrm{FEV}_{1}\right)$, and the $\mathrm{FEV}_{1} / \mathrm{FVC}$ ratio, a portable digital Easy$\mathrm{One}^{\circledast}$ spirometer of the $n d d$ brand was used. The criteria for normal lung test consisted in FVC and $\mathrm{FEV}_{1} \geq 80 \%$ predicted and $F E V_{1} / F V C \geq 0.7$. Spirometric variables were expressed as absolute values and as percentages of predicted normal values, according to Pereira et al. [28].

Before performing the pulmonary function test, pulse oxygen saturation $\left(\mathrm{SpO}_{2}\right)$ and heart rate $(\mathrm{HR})$ were measured with the participant in the supine position and at rest with a pulse oximeter (Oximeter, Model MD300C11).

\section{Assessment of diaphragmatic mobility by digital radiography fluoroscopy}

Diaphragmatic mobility was assessed through examination of digital X-ray fluoroscopy in anteroposterior incidence (AP) by two raters. To perform the test, a Siemens fluoroscopy device, model Lumino RF Classic was used at a distance of $1.15 \mathrm{~m}$ from the image intensifier and X-ray tube.

Subjects were placed on a radioscopic table in a supine position with their feet supported to restrict their movement on the table, and a radiopaque graduation ruler was placed under the subjects' trunks in a longitudinal direction and in the craniocaudal direction. Before performing the fluoroscopy by digital radiography to evaluate the 
diaphragmatic motion, training in diaphragmatic breathing was provided. The goal was to develop diaphragmatic proprioception movement and enable the evaluation of diaphragm maximum amplitude during fluoroscopic digital X-ray examination. Afterwards, we measured slow vital capacity (SVC) using a Wright Respirometer Brit. ${ }^{\circ}$ UK ventilometer, before and during the examination of digital X-ray fluoroscopy with subjects in a supine position. Three manoeuvers were performed before radiographic exposure, and the highest value was recorded for later comparison with what would be assessed during the examination of diaphragmatic mobility. During the examination of digital $\mathrm{X}$-ray fluoroscopy, each rater asked the subjects, while exhaling, to breathe using TLC (total lung capacity) until they approached RV (residual volume), and then, upon exhaling, to breathe from RV until approaching TLC. The values of the SVC manoeuvers obtained were compared to each other (before and during the exam), to determine whether the subjects performed the same respiratory effort before and during the evaluation of diaphragmatic mobility. If there was a difference greater than $10 \%$ from the previously obtained value, the examination would be repeated on the same day.

Subjects were evaluated randomly, in a simple raffle, by two expert radiologists (raters A and B) who guided subjects in a standardized way. The raters viewed the diaphragm movement through the display on the fluoroscopy device, which was positioned on the central part of the thorax, viewing both hemidiaphragms at the same time. The images of maximum expiration and inspiration were recorded on the same film, which remained motionless during exams.

\section{Digital measurement of diaphragmatic mobility (DMdig)}

Diaphragmatic mobility $\left(\mathrm{DM}_{\mathrm{dig}}\right)$ was measured by calculating the distance between the diaphragmatic dome in expiration and inspiration for the right and left hemidiaphragms, based on the method described by Saltiel et al. [20]. Initially, the line of MediWorks 8.4.215 software was calibrated using a radiopaque ruler to correct the magnification caused by the divergence of the rays. This calibration was performed by drawing a line with the computer cursor over a distance of $10 \mathrm{~mm}$ on the image of the ruler in the digital radiography, thus determining the actual distance. Then, to measure diaphragmatic mobility, the highest point on the hemidiaphragm in expiration was found and a straight perpendicular line was drawn with the cursor until it met the hemidiaphragm in inspiration finding the distance between the diaphragmatic domes (Fig. 1). This measurement was performed for both right and left hemidiaphragms (RH) and (LH).

\section{Measurement of diaphragmatic mobility by distance (DM $\left.M_{\text {dist }}\right)$}

To measure $\mathrm{DM}_{\text {dist }}$, rater $\mathrm{A}$ identified, on the printed chest radiography, the highest point of the diaphragm during expiration of each hemidiaphragmatic dome, and from this point a line was drawn with a black marker until the hemidiaphragm during inspiration was found. The diaphragm mobility was determined by the distance between the diaphragm dome on expiration and inspiration by the calliper, both on the right side and the left side. To correct the image magnification caused by the divergence of X-rays, a correction formula was used: Corrected mobility $(\mathrm{mm})=$ mobility measure $(\mathrm{mm}) \times 10 /$ graduation on the ruler $(\mathrm{mm})$ [20].

\section{Analysis of the validity}

To assess the validity of the method (criterion validity), we analysed the concurrent validity. The competing method was the method of Saltiel et al. [20], which evaluates diaphragm mobility on the printed radiograph by distance $\left(D_{\text {dist }}\right)$ by means of a calliper. Validity was assessed by relating the first measurement of $\mathrm{DM}_{\text {dig }}$ obtained by rater $\mathrm{A}$ with the measurement using the $\mathrm{DM}_{\text {dist }}$ method by the same rater. We evaluated both right and left hemidiaphragms.

\section{Analysis of reliability}

Measurements of diaphragmatic mobility were assessed soon after scanning the radiograph. The first measurement was used for the analysis of inter-rater reliability of the method (measurements $A_{1}$ and $B_{1}$ ) in the following manner: a measurement taken by rater $A\left(A_{1}\right)$ was correlated with that taken by rater $B\left(B_{1}\right)$. Then, a second measurement was performed for the analysis of inter-rater reliability of the measure as follows: rater A measured the digital radiography fluoroscopy exam performed by rater $B$, obtaining measure $A_{B}$, and rater $B$ measured the digital radiography fluoroscopy exam performed by rater $A$ obtaining measure $B_{A}$. The analysis was performed by correlating measures $A_{B}$ with $\mathrm{B}_{1}$ and $\mathrm{B}_{\mathrm{A}}$ with $\mathrm{A}_{1}$.

The intra-rater reliability of the measurement was assessed by measuring diaphragmatic mobility from the previous examination, after a minimum interval of 7 days and maximum of 20 days from the first measurement ${ }^{25}$. Both raters $\mathrm{A}$ and $\mathrm{B}$ measured the digital radiographs one more time (measures $\mathrm{A}_{2}$ and $\mathrm{B}_{2}$ ) performed at the beginning of the study. Inter-rater reliability was also examined in the second assessment.

Raters A and B did not know who conducted the radiographs and did not have access to the values of the other's assessments. The results were analysed after completion of all assessments. 


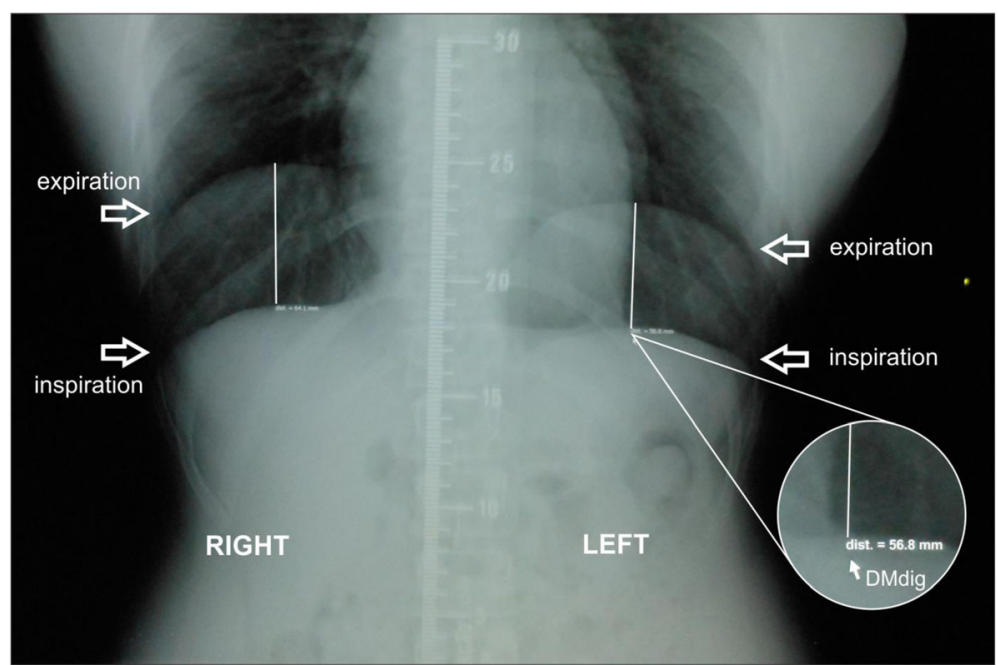

Fig. 1 Measurement of diaphragm mobility obtained by the software. Digital radiography of the chest in anteroposterior view (AP) during maximal expiration and maximal inspiration conducted on the same film. Measurements of the mobility of right and left hemidiaphragms were obtained by the software of the device using the ruler on the image for calibration. Source: author's own production

\section{Statistical analysis}

Data were analysed using SPSS for Windows, version 20.0 (IBM SPSS Statistics, IBM, Armonk, NY, USA) and GraphPad Prism 5.1 program and treated with descriptive analysis (mean and standard deviation) and inferential analysis. Shapiro-Wilk test was used to analyse data normality.

Pearson correlation coefficient and intraclass correlation coefficient (two-way random model, with absolute agreement - $\left.\mathrm{ICC}_{[2.1]}\right)$ were used to assess the correlation between the digital method $\left(\mathrm{DM}_{\mathrm{dig}}\right)$ and the method of distance $\left(\mathrm{DM}_{\text {dist }}\right)$. The analyses of inter-rater and intra-rater reproducibility were determined using intraclass correlation coefficient (two-way random model, with absolute agreement - $\left.\mathrm{ICC}_{[2.1]}\right)$ and confidence interval (CI) of 95\% [8]. Reliability was interpreted as the magnitude of Portney and Watkins coefficient of reliability [8]: 'poor' for coefficients under 0.50 , 'moderate' for coefficients between 0.50 and 0.75 , and 'good' for coefficients above 0.75. ICC varies from 0.00 to 1.00 , and values close to 1.00 show strong reliability. Bland-Altman plot was also used to allow better visualization of agreement between the individual measures [29].

Wilcoxon test was used to compare the values of slow vital capacity before and during radiographic exposures for each rater. Paired $\mathrm{T}$ test was used to compare the mobility of the right and left hemidiaphragms. The $\mathrm{T}$ test for independent samples was used to compare the values of diaphragmatic mobility between male and female participants. The significance level for statistical treatment was $5 \%(p<0.05)$.

\section{Results}

Twenty-six healthy adults, 17 women (65.4\%) and 9 men (34.6\%) were evaluated, with a mean age of $28.19 \pm 6.1$ years, mean BMI 23.89 \pm 4.2 , classified as normal, healthy and with normal pulmonary function (Table 1). No subject refused to participate or desisted during assessments.

A high correlation was found between $\mathrm{DM}_{\text {dig }}$ and $\mathrm{DM}_{\text {dist }}$ for the mobility of the right hemidiaphragm (RH) $(r=0.97$, $p=0.00)$ and the left one (LH) $(r=0.88, p=0.00)$. There was good reliability for mobility in both hemidiaphragms $\left(\mathrm{RH}: \mathrm{ICC}_{[1,2]}=0.98,95 \% \mathrm{CI}=0.96\right.$ to $0.99 ; \mathrm{LH}: \mathrm{ICC}_{[2,1]}=$ 0.93, 95\% CI $=0.84$ to 0.97 ) (Fig. 2).

In the inter-raters analysis, in the first assessment there was good reliability for $\mathrm{RH}$ and moderate in $\mathrm{LH}$.

Table 1 Anthropometric and cardiopulmonary characteristics of the study participants

\begin{tabular}{lc}
\hline Variables & Average \pm standard deviation variables $(n=26)$ \\
\hline Age (years) & $28.19 \pm 6.1$ \\
Body mass $(\mathrm{kg})$ & $68.14 \pm 16.7$ \\
Height $(\mathrm{m})$ & $1.68 \pm 0.1$ \\
$\mathrm{BMI}\left(\mathrm{kg} \cdot \mathrm{m}^{-2}\right)$ & $23.89 \pm 4.2$ \\
$\mathrm{HR}(\mathrm{bpm})$ & $72.61 \pm 9.7$ \\
$\mathrm{SpO}_{2}(\%)$ & $98.35 \pm 0.6$ \\
$\mathrm{FVC}^{(\%}$ predicted) & $92.85 \pm 7.7$ \\
$\mathrm{FEV}_{1}(\%$ predicted) & $94.73 \pm 7.1$ \\
$\mathrm{FEV}_{1} / \mathrm{FVC}(\mathrm{L})$ & $0.91 \pm 0.2$ \\
\hline
\end{tabular}

Values were express as mean and standard deviation

$n$ number of subjetcs, $k g$ lbs, $m$ meters, $B M l$ body mass index, HR heart rate, bpm: beats per minute, SpO2 oxygen saturation by pulse, FVC (\%predicted): Estimated percentage of FVC, FEV1 (\%predicted): Estimated percentage of forced expiratory volume in one second, $L$ liters 

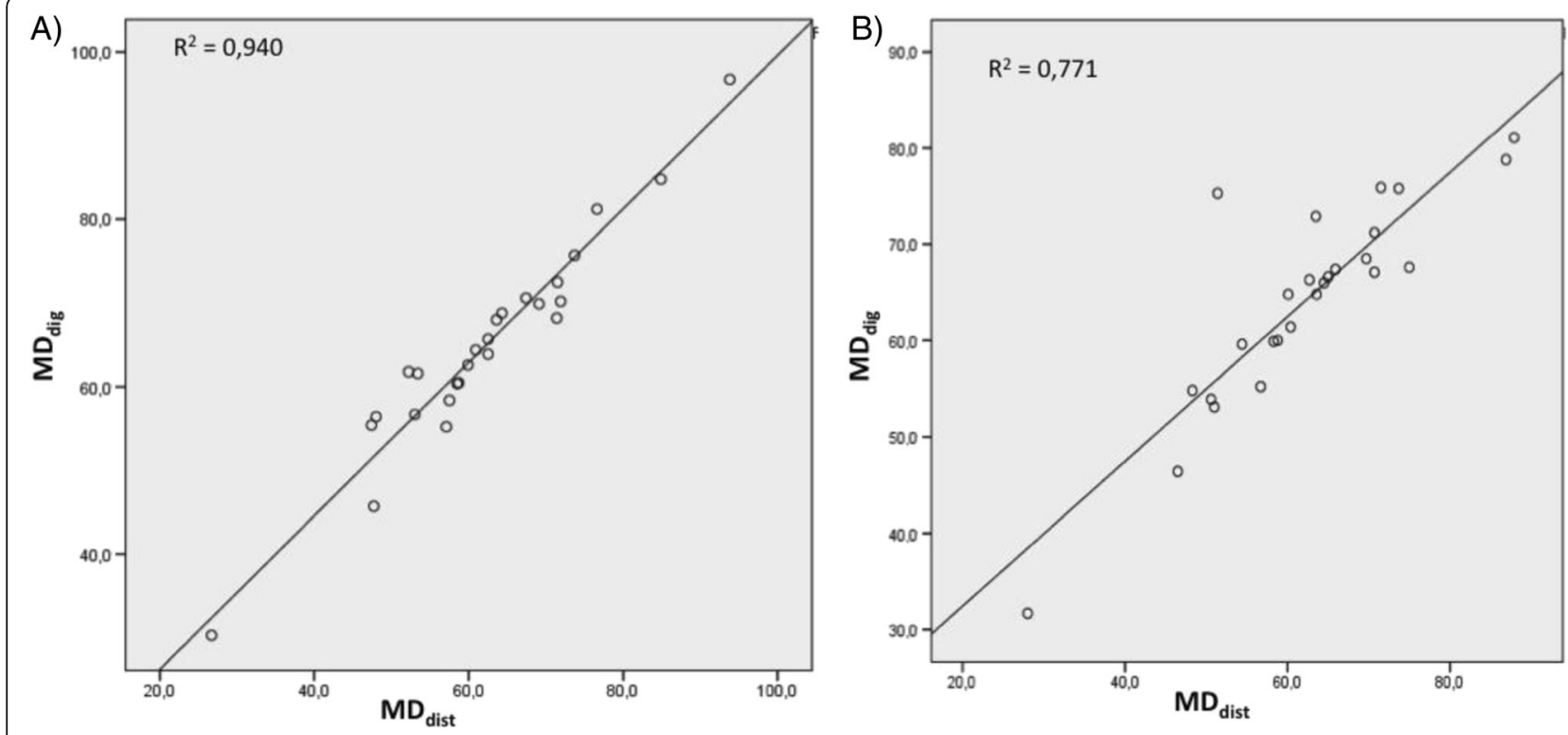

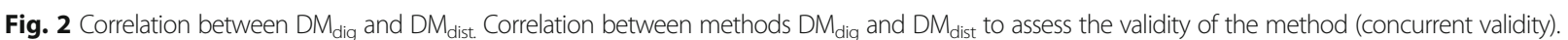
The concurrent validity by relating the first measurement of DMdig obtained by rater A with the measurement using the DMdist method by the same rater. a Right hemidiaphragm. $\mathbf{b}$ Left hemidiaphragm. $\mathrm{DM}_{\text {dig: }}$ digital diaphragmatic mobility. $\mathrm{DM}_{\text {dist: }}$ diaphragmatic mobility by distance

In the second assessment, there was good reliability for mobility in both hemidiaphragms. There was good intrarater reliability of mobility in both $\mathrm{RH}$ and $\mathrm{LH}$ for rater A. Similar results were found in the measurements obtained by rater $\mathrm{B}$ in assessing $\mathrm{RH}$ and $\mathrm{LH}$. The analyses of interrater and intra-rater reliability for digital diaphragmatic mobility of RH and LH are described in Table 2.

To demonstrate higher reliability, we also evaluated inter-rater reproducibility of the measurement, where rater $\mathrm{A}$ measured the examination performed by rater $\mathrm{B}$, yielding measure $A_{B}$ and we compared this with measure $B_{1}$. For this analysis there was good reliability for the ratings of $\mathrm{RH}$ and $\mathrm{LH}\left(\mathrm{ICC}_{[2,1]}=0.98,95 \% \mathrm{CI}=0.96\right.$ to 0.99 ; $\mathrm{ICC}_{[2,1]}=0.95,95 \% \mathrm{CI}=0.90$ to 0.98 , respectively).

Table 2 Inter-rater and intra-rater reliability of the mobility measurement of the right and left hemidiaphragms method

\begin{tabular}{|c|c|c|c|}
\hline Variables & & $\mathrm{ICC}[2,1]$ & $\mathrm{Cl} 95 \%$ \\
\hline \multicolumn{4}{|l|}{ Right hemidiaphragm } \\
\hline \multirow[t]{2}{*}{ Inter-rater reliability } & $1^{\mathrm{a}}$ assess & 0.89 & $0.76-0.95$ \\
\hline & $2^{\mathrm{a}}$ assess & 0.84 & $0.68-0.93$ \\
\hline \multirow[t]{2}{*}{ Intra-rater reliability } & rater $\mathrm{A}$ & 0.83 & $0.66-0.92$ \\
\hline & rater $B$ & 0.89 & $0.76-0.95$ \\
\hline \multicolumn{4}{|l|}{ Left hemidiaphragm } \\
\hline \multirow[t]{2}{*}{ Inter-rater reliability } & $1^{\mathrm{a}}$ assess & 0.73 & $0.48-0.87$ \\
\hline & $2^{\mathrm{a}}$ assess & 0.78 & $0.56-0.89$ \\
\hline \multirow[t]{2}{*}{ Intra-rater reliability } & rater $\mathrm{A}$ & 0.86 & $0.70-0.93$ \\
\hline & rater B & 0.83 & $0.65-0.92$ \\
\hline
\end{tabular}

ICC $[2,1]$ the intraclass correlation coefficient (two-way random model, with absolute and agreement), Cl 95\% confidence interval of $95 \%$
Rater $\mathrm{B}$ also measured the examination performed by rater $A$ to obtain measure $B_{A}$. When comparing it with measure $\mathrm{A}_{1}$, there was good reliability for $\mathrm{RH}\left(\mathrm{ICC}_{[2,1]}=\right.$ $0.98,95 \% \mathrm{CI}=0.96$ to 0.99$)$ and for $\mathrm{LH}\left(\mathrm{ICC}_{[2,1]}=0.86\right.$, $95 \% \mathrm{CI}=0.72$ to 0.94$)$.

According to Bland-Altman plot, there was good concordance between measures of mobility of both $\mathrm{RH}$ and LH, obtained by raters A and B (inter-rater agreement) (Fig. 3), and good concordance between measures of mobility of $\mathrm{RH}$ and $\mathrm{LH}$, obtained by each of the raters (Fig. 4), at two different times (intra-rater agreement). Figure 5 shows that there was good concordance between measures of mobility of $\mathrm{RH}$ and $\mathrm{LH}$, obtained by raters $\mathrm{A}$ and $\mathrm{B}$ when rater $\mathrm{A}$ measured the test conducted by rater $B$ and when rater $B$ measured the test conducted by rater $\mathrm{A}$. There was good concordance because the difference between the measures is the limits of agreement (upper and lower limits). The mean of the measures between raters in all analyses is close to zero, which indicates reproducibility of the measurements. However, when analysing the inter-rater graphics, there was greater dispersion of the means obtained.

There were no differences between the manoeuvers of slow vital capacity (SVC) performed before and during fluoroscopy examinations by radiography by raters $\mathrm{A}$ and $\mathrm{B}$, respectively (before: $3.92 \pm 1.5 \mathrm{~mm}$; during: $4.07 \pm 1.5 \mathrm{~mm}, p=0.57$; before: $3.92 \pm 1.5 \mathrm{~mm}$; during : $4.12 \pm 1.4 \mathrm{~mm}, p=0.46$ ).

The mobility measured in the right $(\mathrm{RH})$ and left $(\mathrm{LH})$ hemidiaphragms by the two raters (A and B) showed no statistically significant difference. The mean values of 


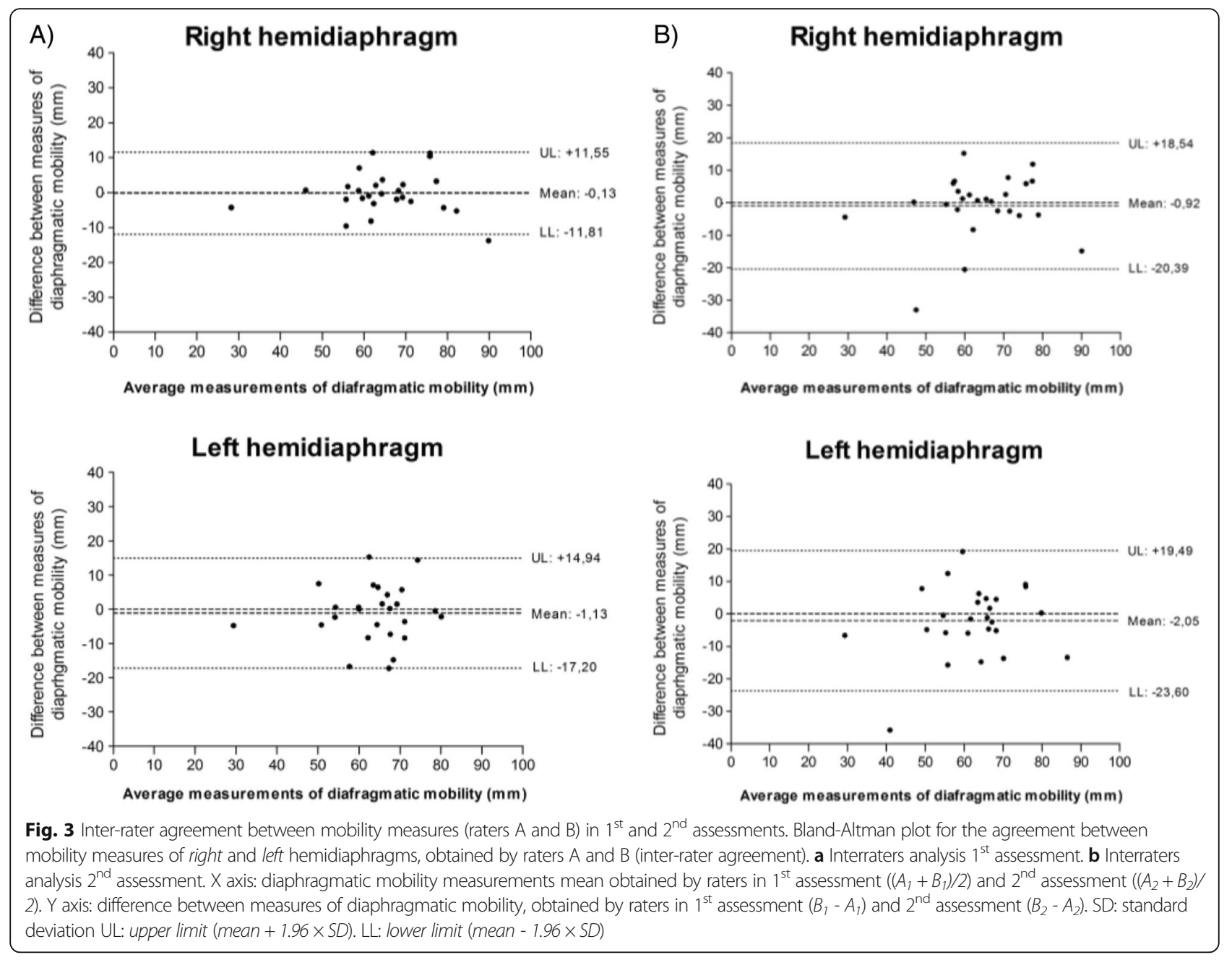

$\mathrm{RH}$ and LH mobility when analysed by rater A were $64.8 \pm 12.6 \mathrm{~mm}$ (30.3 to $96.7 \mathrm{~mm}$ ) and $64.1 \pm 10.8 \mathrm{~mm}$ (31.7 to $92.3 \mathrm{~mm}$ ), respectively and when analysed by rater $\mathrm{B}, 64.7 \pm 12.5 \mathrm{~mm}$ (26.1 to $83.3 \mathrm{~mm}$ ) and $62.9 \pm$ $11.3 \mathrm{~mm}$ (27.0 to $81.5 \mathrm{~mm}$ ), respectively. There was no statistically significant difference in the mobility of $\mathrm{RH}$ and $\mathrm{LH}$ measured by the two raters: $\mathrm{A}(p=0.69)$ and $\mathrm{B}(p=0.41)$.

\section{Discussion}

This study demonstrated that the digital X-ray fluoroscopy method is valid and reliable for measuring mobility of the left and right hemidiaphragms in healthy adults. In clinical practice, the use of reliable instruments is essential for ensuring reliable results [9].

Fluoroscopy is the most accurate method for evaluating diaphragm dysfunction as it assesses the diaphragmatic motion in real time [5], but some measures require a video be made of the image [10, 11 , which is not always available in fluoroscopy equipment, or they require calculations involving complex procedures to determine diaphragmatic motion [13].

Thus, the proposal of this study is innovative because it verifies the validity and the reliability of a new method of fluoroscopy and a new way of measuring diaphragmatic movement. For this, we applied a common resource used in clinical practice, which is the Xray, and we innovated by using fluoroscopy associated with digital radiography. This method is easy to apply and measure, has a low cost because it is not necessary to print the radiography, and it can be another tool for professionals in the health assessment of patient's diaphragmatic mobility.

Our proposal was to perform a digital measurement using software that is routinely used in medical radiological practice, but this is a unique way for evaluating diaphragmatic mobility in the scientific community. The measurement of diaphragmatic motion using the scanned image $\left(\mathrm{DM}_{\text {dig }}\right)$ is simple and practical to perform, and proved to be reliable. We emphasize that the digitization of the exam is a technology that 


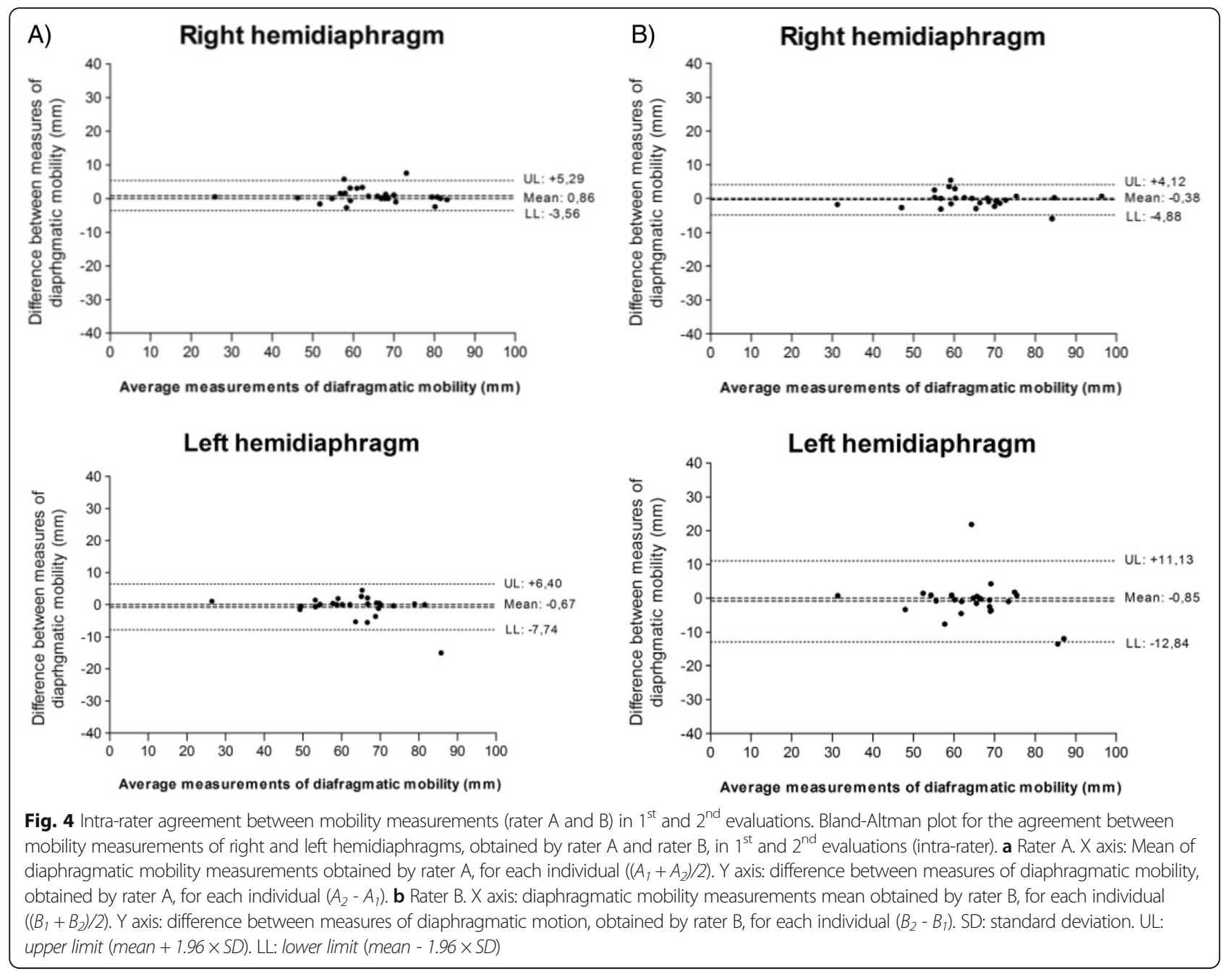

generates practicality, quality in analysis and makes storage easier in examinations, requiring no physical space. Moreover, it enables sharing among several professionals for the consultation and discussion of clinical cases.

This study found good reliability in the method analyses of diaphragmatic mobility for both raters A and B. There was good inter-rater reliability for the analysis of measure for $\mathrm{RH}$ and $\mathrm{LH}$. Thus, we find that digital X-ray fluoroscopy is a reliable method for measuring diaphragmatic mobility, because a measure is considered reliable if the ICC is greater than 0.75 [8].

In the inter-rater analysis of the Bland-Altman plot in Fig. 3, a greater dispersion of the measures was observed. However, in Fig. 5 when rater A measured the test conducted by rater $\mathrm{B}$ and when rater $\mathrm{B}$ measured the test conducted by rater $\mathrm{A}$, there was lower dispersion of data. Possibly, this difference in dispersion of data between the two analyses was due to the fact that, in the first measurement (Fig. 3), the rater performed the test and also assessed the measure.
In Fig. 5 the raters only had to perform the digital measurement of diaphragmatic mobility $\left(\mathrm{DM}_{\mathrm{dig}}\right)$ in the previously undertaken test. Therefore, we suggest that the same rater perform the measurement of diaphragmatic motion when comparing pre- and post-treatment, ensuring a lower bias between measurements, as our results show lower dispersion of data in intra-rater reliability.

When we observe the correlation between measures in the Bland-Altman plots (Figs. 3, 4 and 5), there was better agreement for the RH. This difference may have happened due to the proximity of the $\mathrm{LH}$ to the heart. Considering that the heart is a dynamic organ with involuntary contraction, at the time of the expiratory pause, a cardiac muscle contraction may have occurred during the evaluation by one of the raters, thereby altering the position of the left hemidiaphragm and consequently the location of the highest expiration point. However, it is important to note that the evaluation method of diaphragmatic mobility is reliable to assess both right and left hemidiaphragms, but the rater should choose the RH, if possible, because the agreement was better. 


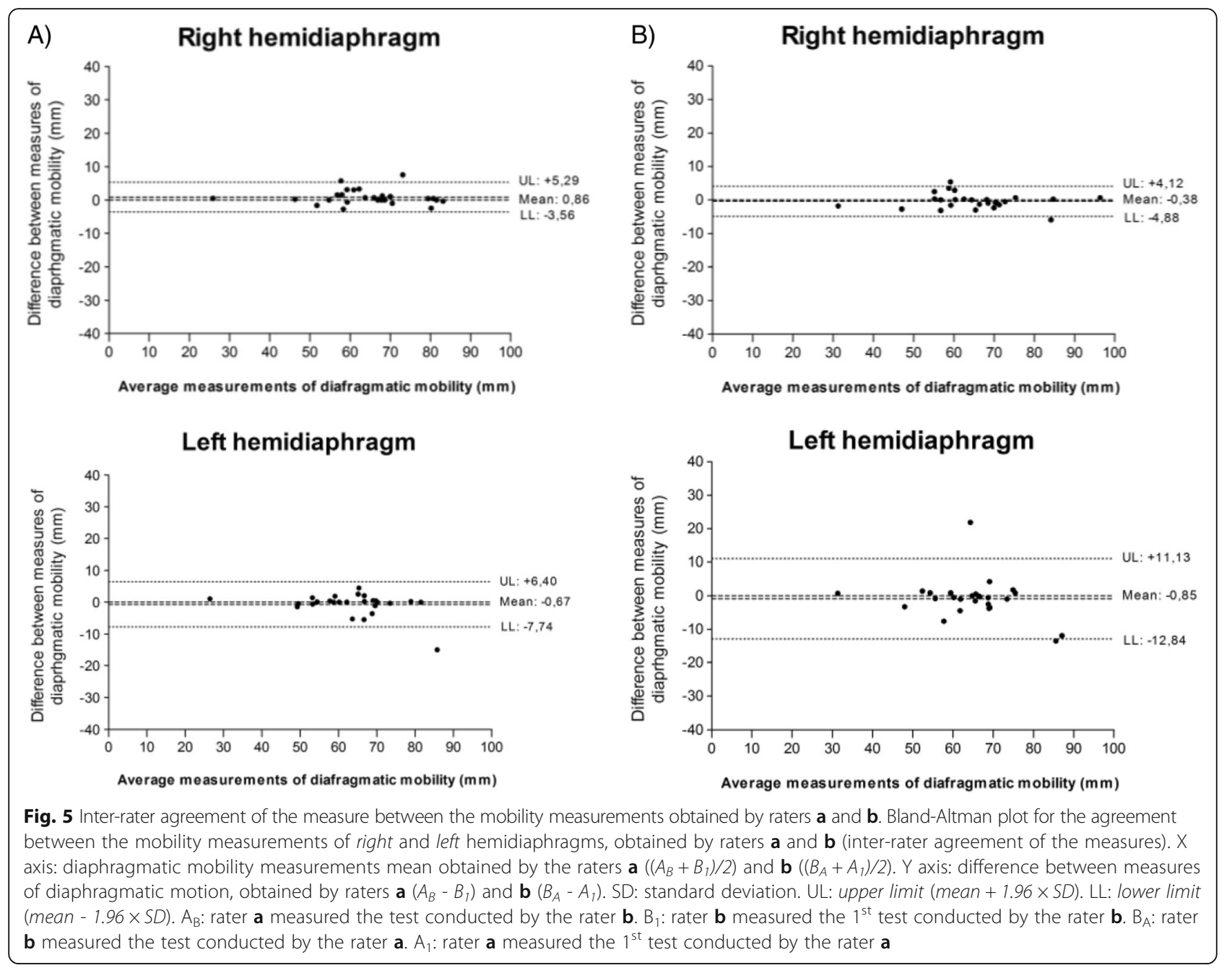

This study found a high variability in the amount of diaphragmatic motion (from 30.3 to $96.7 \mathrm{~mm}$ ), similar to other studies [14, 15, 21]. Kantarci et al. [30] found variability of 25 to $84 \mathrm{~mm}$ for $\mathrm{RH}$, and of 24 to $81 \mathrm{~mm}$ for LH, while in Gerscovich et al. [4], variability from 16.7 to $92 \mathrm{~mm}$ was found for $\mathrm{RH}$, and 38 to $96 \mathrm{~mm}$ for LH. This variability may be related to BMI and age, because according to Kantarci et al. [30], subjects with low weight and younger than 30 have lower diaphragmatic mobility.

In this study there was no difference between diaphragmatic mobility for $\mathrm{RH}$ and $\mathrm{LH}$, a result similar to data obtained in other studies by our group [20]. We also found no difference in diaphragmatic excursion between men and women. The studies by Bousseges et al. [15] and Kantarci et al. [30] found differences between diaphragmatic mobility between men and women. However, Grams et al. [14] and Saltiel et al. [20] found no such differences. This is possibly due to the sample size because the studies by Bousseges et al. [15] and Kantarci et al. [30] had a large number of participants (210 and 164 subjects, respectively), whereas Grams et al. [14] and Saltiel et al. [20] had a smaller number of about 40 subjects.

The mean values of RH mobility were $64.90 \pm 12.9 \mathrm{~mm}$, and $63.95 \pm 11.7 \mathrm{~mm}$ for LH. According to Simon et al. [21], most healthy adults have diaphragm mobility $\geq$ $30 \mathrm{~mm}$. Other studies have found amounts similar to those in our research of diaphragmatic mobility in healthy adults $[12,14]$. There are, however, no reference values for diaphragmatic mobility in the literature.

When performing an examination, it is relevant to consider the acceptability and repeatability of the measurement. In the evaluation of diaphragmatic mobility by fluoroscopy, digital radiography is possible by analysing the acceptability of the examination to verify SVL; however, due to radiation it is not feasible to evaluate the repeatability of the measure. Despite this methodological limitation, it is possible to ensure the maximum movement of the diaphragm through the standardization of the evaluator's guidelines, previous diaphragmatic training, and by obtaining the same SVL during the test. 
In clinical practice, a change in diaphragm movement is often found, with a reduction in mobility or muscle paralysis, which may be due to several factors such as: changes in the muscle itself or neuromuscular conduction, dysfunction in the central nervous system, muscular dystrophy, muscle injury by trauma, phrenic nerve injury, chronic obstructive pulmonary disease, thoracic or abdominal diseases that interfere with their mobility, such as atelectasis or pleural effusions. The study of evaluation methods for diaphragmatic motion is important to better detect and diagnose diaphragm dysfunction [2-5]. A limitation of our study was to evaluate diaphragmatic mobility only in healthy subjects. Therefore, new studies for the validation of the method in patient populations would be relevant, aiming at creating a classification scale of diaphragm dysfunction severity.

Since the diaphragm is the most important respiratory muscle for pulmonary ventilation, it is essential to understand the functional condition of this muscle and its possible changes to establish therapeutic strategies to restore or improve its mobility and thus provide improved functionality and quality of life for the patient $[1-3,6]$.

\section{Conclusion}

The results showed that fluoroscopy by digital radiography method is a valid and reliable instrument to assess the mobility of right and left hemidiaphragms of healthy adults.

\begin{abstract}
Abbreviations
1st: First evaluation; 2nd: Second evaluation; AP: Anteroposterior incidence; BMl: Body mass index; Bpm: Beats per minute; Cl: Confidence interval; DMdig: Diaphragmatic mobility digital; DMdist: Diaphragmatic mobility by distance; FEV1 (\%predicted): Estimated percentage of forced expiratory volume in the first second; FEV1: Forced expiratory volume in the first second; FEV1/FVC: Ratio between forced expiratory volume in the first second and forced vital capacity; FVC (\%predicted): Estimated percentage of forced vital capacity; FVC: Forced vital capacity; HR: Heart rate; kg: Kilograms; L: Litre; LH: Left hemidiaphragms; LL: Lower limit; M: Meter; mm: Millimeter; $\mathrm{RH}$ : Right hemidiaphragms; RV: Residual volume; $\mathrm{SpO}_{2}$ : Oxygen saturation; SVC: Slow vital capacity; TLC: Total lung capacity; UL: Upper limit; ZCC: Intraclass correlation coeficiente
\end{abstract}

\section{Acknowledgments}

We appreciate the partnership with the clinic Lâmina Medicina Diagnóstica. Study carried out in the Laboratório de Fisioterapia Respiratória (LAFIR), Universidade do Estado de Santa Catarina (UDESC), Florianópolis - SC, Brazil.

\section{Funding}

Not applicable.

\section{Availability of data and materials}

Due to the privacy policy of patients, we can't openly release the dataset of questionnaire survey underlying the conclusions of the paper available in public. A truncated dataset after eliminating all potentially identifiable features may be provided on an individual request basis.

\section{Authors' contributions}

This study presents a new tool to evaluate the diaphragmatic mobility that has proved to be valid and reproducible. We believe it will be widely used in clinical practice, for the ease and speed of acquisition of the measure. All authors read and approved the final manuscript.

\section{Competing interests}

The authors declare that they have no competing interests.

\section{Consent for publication}

No patient identifiable material is presented.

Ethics approval and consent to participate

The study was approved by the Research Ethics Committee of the Universidade do Estado de Santa Catarina (UDESC), Brazil, and all subjects provided written informed consent.

\section{Publisher's Note}

Springer Nature remains neutral with regard to jurisdictional claims in published maps and institutional affiliations.

\section{Author details}

${ }^{1}$ Physical Therapy Department,Santa Catarina State University (UDESC), Florianopolis, SC, Brazil. 'Lamina Medicine Diagnostis Clinic, Florianopolis, SC, Brazil. ${ }^{3}$ Federal University of Santa Catarina, Florianopolis, SC, Brazil. ${ }^{4}$ Physical Therapy Department, Rehabilitation Service, Hospital Sírio Libanês, São Paulo, SP, Brazil. ${ }^{5}$ Santa Catarina State University (UDESC), Rua Pascoal Simone, 358, Coqueiros, Florianópolis, SC, BrazilCEP: 88080-350.

Received: 11 April 2016 Accepted: 28 March 2017

Published online: 17 April 2017

\section{References}

1. Yamaguti WP, Claudino RC, Neto AP, Chammas MC, Gomes AC, Salge JM, et al. Diaphragmatic breathing training program improves abdominal motion during natural breathing in patients with chronic obstructive pulmonary disease: a randomized controlled trial. Arch Physic Med Rehab. 2012;93(4): 571-7. http://dx.doi.org/10.1016/j.apmr.2011.11.026.

2. Kang HW, Kim TO, Lee BR, Yu JY, Chi SY, Ban HJ, et al. Influence od diaphragmatic mobility in hypercapnia in patients with chronic obstrutive pulmonar disease. J Korean Med Sci. 2011;26(9):1209-13. http://dx.doi.org/ 10.3346/jkms.2011.26.9.1209.

3. Ayoub J, Cohendy R, Prioux J, Ahmaidi S, Bourgeois JM, Dauzat M, et al. Diaphragm moviment before and after cholecystectomy: a sonographic study. Anesth Analg. 2001;92(3):755-61. https://www.ncbi.nlm.nih.gov/ pubmed/?term=Diaphragm+moviment+before+and+after +cholecystectomy\%3A+a+sonographic+study.

4. Gerscovich EO, Cronan M, McGahan JP, Jain K, Jones CD, McDonald C. Ultrasonographic evaluation of diaphragmatic motion. J Ultrasound Med. 2001;20(6):597-604.

5. Gierada DS, Slone RM, Fleishman MJ. Imaging evaluation of the diaphragm. Chest SurgClin N Am. 1998:8(2):237-80.

6. Reid WD, Dechman G. Considerations when testing and training the respiratory muscles. PhysTher. 1995;75(11):971-82.

7. Gadotti IC, Vieira ER, Magee DJ. Importance and clarification of measurement properties in rehabilitation. Rev bras Fisioter. 2006;10(2):137-46.

8. Portney GL, Watkins PM. Reliability. In: Portney GL, Watkins PM, editors. Foundations of clinical research application to pratice. New Jersey: Pearson Prentice Hall; 2008. p. 61-75.

9. Kimberlin $\mathrm{CL}$, Winterstein AG. Validity and reability of measurement instruments used in research. Am J Health Syst Pharm. 2008;65(23):2276-84. http://dx.doi.org/10.2146/ajhp070364.

10. Yi LC, Nascimento OA, Jardim JR. Reliability of an analysis method for measuring diaphragm excursion by means of direct visualization with videofluoroscopy. ArchBronconeumol. 2011;47(6):310-4.

11. Kleinman B, Frey K, VanDrunen M, Sheikh T, DiPinto D, Mason R, Smith T. Motion of the diaphragm in patients with chronic obstructive pulmonary disease while spontaneously breathing versus during positive pressure breathing after anesthesia and neuromuscular blockade. Anestesiology. 2002;97:298-305.

12. Unal O, Arslan H, Uzum K, Osbay B, Sakaria ME. Evaluation of diaphragmatic movement with MR fluoroscopy in chronic obstructive pulmonary disease. J Clin Imaging. 2000;24:347-50.

13. Verschakelen JA, Deschepper K, Jiang TX, Demedts M. Diaphragmatic displacement measured by fluoroscopy and derived by respitrace. J Appl Physiol. 1989;67(2):694-8. 
14. Grams ST, Saltiel RV, Pedrini A, Mayer AF, Schivinski CIS, Paulin E. Assesment of the reproducibility of the indirect ultrasound method of measuring diaphragm mobility. Clin Physiol Funct Imaging. 2014;34:18-25.

15. Boussuges A, Gole Y, Blanc P. Diaphragmatic motion studied by m-mode ultrasonography: methods, reproducibility, and normal values. Chest. 2009; 135(2):391-400. http://dx.doi.org/10.1378/chest.08-1541.

16. Leung JC, Nance ML, Schwab CW, Miller Jr WT. Thickening of the diaphragm: a new computed tomography sign of diaphragm injury. J Thorac Imaging. 1999;14(2):126-9.

17. Iwasawa T, Yoshiike Y, Saito K, Kagei S, Gotoh T, Matsubara S. Paradoxical motion of the hemidiaphragm in patients with emphysema. J Thorac Imaging. 2000;15(3):191-5.

18. Plathow C, Ley S, Fink C, Puderbach M, Heilmann M, Zuna I, Kauczor HU Evaluation of chest motion and volumetry during the breathing cycle by dynamic MRI in healthy subjects: comparison with pulmonary function tests. Investig Radiol. 2004;39(4):202-9.

19. Kotani T, Minami S, Takahashi K, Isobe K, Nakata Y, Takaso M, Inoue M, Maruta T. An analysis of chest wall and diaphragm motions in patients with idiopathic scoliosis using dynamic breathing MRI. Revista Spine. 2004;29(3):298-302.

20. Saltiel RV, Grams ST, Pedrini A, Paulin E. High reliability of measure of diaphragmatic mobility by radiographic method in healthy individuals. Braz J PhysTher. 2013:17(2):128-36. doi: 10.1590/S1413-35552012005000076.

21. Simon G, Bonnell J, Kazantzis G, Waller RE. Some radiological observations on the range of movement of the diaphragm. Clin Radiol. 1969;20(2):231-3. http://dx.doi.org/10.1016/50009-9260(69)80181-9.

22. Roberts HC. Imaging the diaphragm. ThoracSurgClin. 2009:19(4):431-50. http://dx.doi.org/10.1016/j.thorsurg.2009.08.008.

23. Bonett DG. Sample size requirements for testing and estimating coefficient alpha. J Educ Behav Stat Winter. 2002;27(4):335-40.

24. Fleiss JL. Design and analysis of clinical experiments. New York: Wiley; 1999. p. 2-27.

25. Hulley SB. Delineando a pesquisa clínica: uma abordagem epidemiológica. Porto Alegre: Artmed; 2008. p. 23-4.

26. World Health Organization. WHO obesity technical report series. obesity: preventing and managing the global epidemic. report of a world health organization consultation. Geneva: World Health Organization; 2000. p. 284-56.

27. Miller MR. Series "ATS/ERS task force: standardisation of lung function testing". Standardisations of spirometry. Eur Respir J. 2005;26:319-38. http://dx.doi.org/10.1183/09031936.05.00034805.

28. Pereira CAC, Rodrigues SC, Sato T. Novos valores de referência para espirometria forçada em brasileiros adultos de raça branca. J Bras Pneumol. 2007;33(4):397-406. http://dx.doi.org/10.1590/S1806-37132007000400008

29. Bland JM, Altman DG. Statistical methods for assessing agreement between two methods of clinical measurement. Lancet. 1986;327(8476):307-10. http://dx.doi.org/10.1016/S0140-6736(86)90837-8.

30. Kantarci F, Mihmanli I, DemireL MK, Harmanci K, Akman C, Aydogan F, et al. Normal diaphragmatic motion and the effects of body composition: determination with m-mode sonography. J Ultrasound Med. 2004;23(2):255-60.

\section{Submit your next manuscript to BioMed Central and we will help you at every step:}

- We accept pre-submission inquiries

- Our selector tool helps you to find the most relevant journal

- We provide round the clock customer support

- Convenient online submission

- Thorough peer review

- Inclusion in PubMed and all major indexing services

- Maximum visibility for your research

Submit your manuscript at www.biomedcentral.com/submit
Biomed Central 